\title{
Fears and beliefs of people living with rheumatoid arthritis: a systematic literature review
}

\author{
Penélope Esther Palominos ${ }^{1,2^{*}}$, Andrese Aline Gasparin ${ }^{1}$, Nicole Pamplona Bueno de Andrade ${ }^{1}$, \\ Ricardo Machado Xavier ${ }^{1,2}$, Rafael Mendonça da Silva Chakr ${ }^{1,2}$, Fernanda Igansi ${ }^{1}$ and Laure Gossec ${ }^{3}$
}

\begin{abstract}
Objective: To assess the main fears and beliefs of people with rheumatoid arthritis (RA) and their effect on treatment outcomes;

Methods: A systematic literature review was conducted in Pubmed/Medline; original articles published up to May 2017, reporting fears and/or beliefs of adult patients with RA were analyzed. Fears and beliefs were collected by two independent researchers and grouped into categories.

Results: Among 474 references identified, 84 were analyzed, corresponding to 24,336 RA patients. Fears were reported in $38.4 \%$ of the articles $(N=32 / 84)$ : most studies described fears related to pharmacological therapy $(50.0 \%, N=16 / 32)$ and fear of disability $(28.1 \%, N=9 / 32)$. Beliefs were reported in $88.0 \%$ of articles $(N=74 / 84)$ and were found to moderate the patient-perceived impact of RA in $44.6 \%(N=33 / 74)$, mainly the emotional impact $(18.9 \%, N=14 / 74)$; measures of function, quality of life, fatigue and pain were also found to be affected by patients' beliefs in $8.1 \%(N=6 / 74), 6.8 \%(N=5 / 74), 2.7 \%$ $(N=2 / 74)$ and $2.7 \%(N=2 / 74)$ of the articles, respectively. Beliefs about therapy were linked to adherence in $17.6 \%$ of articles $(N=13 / 74)$ and beliefs about cause of RA predicted coping patterns in $12.2 \%$ of publications $(N=9 / 74)$. Only $9.5 \%$ $(N=8 / 84)$ of articles reported fears and/or beliefs of patients living outside Europe and North America: there was only one work which recruited patients in Latin America and no article included patients from Africa.
\end{abstract}

Conclusion: In RA, patients' beliefs are linked to impact of disease and non-adherence. Further research is needed on fears/ beliefs of patients living outside Europe and North America.

Keywords: Fears, Beliefs, Rheumatoid arthritis

\section{Background}

Despite the growing interest of rheumatologists into the patients' perspective in the last decade and the wide use of patient-reported outcomes in the assessment of Rheumatoid Arthritis (RA), the main fears and beliefs of this group of patients and their consequences on treatment outcomes are unclear [1,2]. This theme has been explored through qualitative and quantitative methodology in different populations with a large amount of

\footnotetext{
* Correspondence: penelopepalominos@gmail.com

${ }^{1}$ Universidade Federal do Rio Grande do Sul (UFRGS), Programa de Pós Graduação em Ciências Médicas (PPGCM), Rua Ramiro Barcelos 2400, segundo andar, Porto Alegre 90035-903, Brazil

${ }^{2}$ Department of Rheumatology, Hospital de Clinicas de Porto Alegre, Rua Ramiro Barcelos 2350, sexto andar, Porto Alegre 90035-903, Brazil Full list of author information is available at the end of the article
}

fears and beliefs being reported and even conflicting data being published about the consequences of patients' perceptions [3-5]. While some authors, for example, found an association between higher concern scores about drugs with non-adherence, other found no association between patients' beliefs and maintenance of diseasemodifying antirheumatic drugs (DMARDs) [3-5].

The subjectivity of fear and beliefs, the small patient samples in some studies and the limited knowledge about the consequences of patients' fears and beliefs on treatment outcomes may lead some rheumatologists to be unconvinced about the importance of the theme.

A systematic literature review would help to obtain an overview. Furthermore, cultural background may play a role in fears and beliefs $[6,7]$. 
This systematic literature review aimed to obtain an overview on fears and beliefs of patients living with RA reported in the medical literature, as well as assess the consequences of fears and beliefs on impact of disease and treatment outcomes. It also investigated if published studies reporting fears and beliefs are representative of all continents.

\section{Methods}

A systematic literature review was conducted in PubMed Medline up to 25 May 2017, using the Preferred Reporting Items for Systematic Reviews and Meta-Analyses statement as a guideline in the development of the study protocol and reporting of the results [8].

\section{Search and selection process}

Publications were identified through the following research strategy:

("interviews as topic"[MeSH Terms] OR "narration"[MeSH Terms] OR "surveys and questionnaires"[MeSH Terms] OR "qualitative research"[MeSH Terms]) AND ("arthritis/psychology" $[\mathrm{MeSH}$ Terms] OR "arthritis, rheumatoid"[MeSH Terms]) AND ("fears"[All Fields] OR "beliefs"[All Fields] OR "attitude to health/psychology"[MeSH Terms] OR "behavior and behavior mechanisms/psychology"[MeSH Terms] OR "affective symptoms/psychology"[MeSH Terms])

\section{Inclusion criteria}

All original articles reporting fears and/or beliefs of adult patients diagnosed with RA were included in the analysis; fears and beliefs were defined according to the Cambridge English Dictionary respectively as "a strong emotion caused by great worry about something dangerous, painful or unknown that is happening or might happen" and "the feeling of being certain that something exist or is true". These concepts were useful for making the distinction between articles reporting fears/beliefs and articles reporting coping patterns and psychological status. Articles written in English, Spanish, French, Italian and Portuguese and published up to 25 May 2017 were considered.

Both qualitative studies (data obtained through individual interview and/or focus groups), quantitative studies (information obtained through questionnaires) and mixed designs (articles including qualitative and quantitative methods) were included.

When RA and other clinical conditions (i.e. systemic lupus erythematosus, osteoarthritis, chronic pain etc) were included in the same study, the article was included in the analysis only if fears and/or beliefs of patients with RA were described separately from the other clinical condition.

\section{Exclusion criteria}

articles not reporting fears and/or beliefs, articles reporting fears and/or beliefs of patients with other rheumatic and non-rheumatic diseases, articles assessing children's fears and/or beliefs, studies assessing fears and/or beliefs of patients' spouses, partners and caregivers as well as reviews, letters and editorials were excluded.

\section{Data collection}

The selection process was performed by two authors (PEP and AAG) based on the titles and abstracts of the articles, and then on full texts. The articles included were then reviewed by two authors (PEP and NPD) and disagreements were solved by consensus.

\section{General data extraction}

Data were obtained on year of publication, study design (qualitative, quantitative or mixed design), number of patients, sampling method (convenience, consecutive, purposeful, systematic random sample), number of centers recruiting patients, the method used for data collection (individual interview, focus groups, questionnaire or mixed methods). When qualitative methodology was employed, the method used for qualitative analysis and for sample size definition was obtained. Demographic data of participants such as gender, mean age, mean disease duration was recorded for each report.

\section{Collection of fear and beliefs}

Fears were grouped in categories by PEP and LG (e.g. fears related to pharmacological therapy, fear of falling, fear of exercise relating injury, etc.). Beliefs were grouped in categories according to their consequences (e.g. beliefs about cause of disease predicting coping patterns, beliefs about pharmacological therapy affecting adherence, beliefs affecting impact of disease etc.).

\section{Statistical analysis}

Analysis was mainly descriptive; characteristic of articles and patients included were expressed as mean and standard deviation as estimates of central tendency and dispersion, respectively.

Categories of fears and beliefs were presented as number of articles which were included in that category and percentage of articles reporting that specific category among the total number of publication assessing fears or beliefs, respectively. The recruitment of patients worldwide was described as percentage, with the number of articles recruiting patients in each region as numerator and total number of studies reporting that category of fears/beliefs in the denominator. 


\section{Results}

\section{Description of publications and participants}

Of the 474 publications identified by the literature search, 84 were included in the analysis. The list of all articles included in the analysis is provided as Additional file 1.

The main reasons for exclusion were articles assessing fears and/or beliefs from patients with other clinical conditions $(52.3 \%, N=204)$ and articles not assessing fears and/or beliefs (45.6\%, $N=178$ ) (Fig. 1).

The 84 articles considered in the analysis included 24,336 subjects with RA; mean age of participants was $54.9 \pm 5.0$ years old, mean disease duration was $10.7 \pm 6.0$ years and $74.0 \%(N=18,032)$ were females (Table 1).

The sample was recruited by convenience in the majority of analyzed articles $(57.1 \%, N=48)$, followed by the recruitment of consecutive patients $(N=14 ; 16.7 \%)$. Systematic random sampling was described in only $4.8 \%$ of articles $(\mathrm{N}=4)$.

The majority of trials employed exclusively quantitative methodology $(69.0 \%$ of the 84 articles analyzed, $N=58$ ) with the cross sectional design being the most commonly found $(77.6 \%$ of the publications reporting only quantitative methods, $N=45)$. Thirty-one percent $(N=26)$ of the 84 articles employed some method of qualitative analysis (both solely or associated with quantitative methods). Among these 26 articles, the majority described the methodology used for analysis of qualitative data $(55.5 \%, N=15)$ and the inductive thematic analysis/ grounded theory was the most cited $(N=12,80.0 \%$ of those articles describing the methodology used for qualitative analysis) (Table 1). Six articles (23.0\% of the 26 articles employing qualitative methodology) described that the saturation method was used to define the sample size [9].

Fears and/or beliefs were assessed through questionnaires, individual interviews and focus groups in $75.0 \%$ $(N=63), 20.2 \%(N=17)$ and $6.0 \%(N=5)$ of articles, respectively (Table 1 ).

All articles employing quantitative methodology $(N=58)$ assessed beliefs trough questionnaires and more than 50 different tools assessing fears and/or beliefs were described; the most frequently used were the original, and brief versions of the "Illness Perception Questionnaire" (IPQ) $[10,11](22.4 \%, N=13)$ and the "Beliefs about Medicines Questionnaire" (BMQ) (18.9\%, $N=11)$ [12].

Disagreements between the two authors collecting the characteristics of publications, demographic data
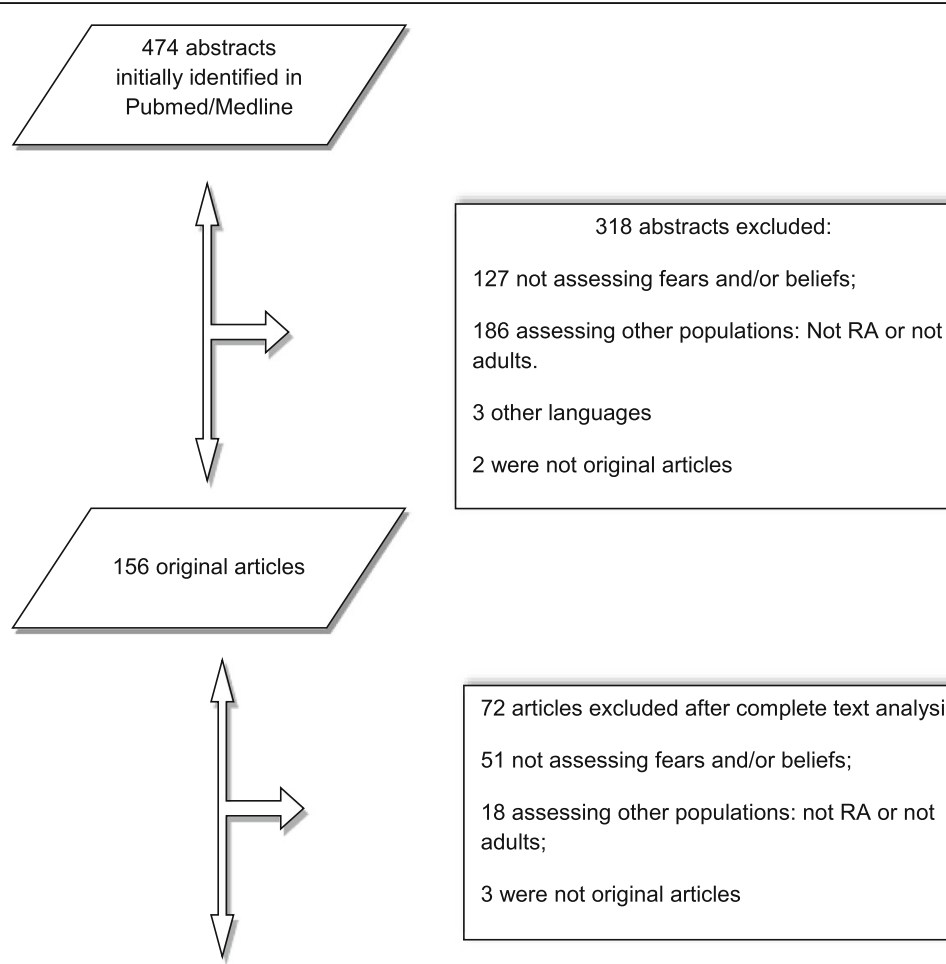

72 articles excluded after complete text analysis:

51 not assessing fears and/or beliefs;

18 assessing other populations: not RA or not adults;

3 were not original articles

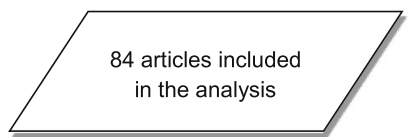

Fig. 1 Flow chart showing the selection of articles that reported fears and/or beliefs of patients with RA 
Table 1 Characteristics of the publications and patients included in the analysis

\begin{tabular}{|c|c|c|c|c|}
\hline & $\begin{array}{l}\text { All articles } \\
(N=84)\end{array}$ & $\begin{array}{l}\text { Studies employing only } \\
\text { qualitative methodology } \\
N=18\end{array}$ & $\begin{array}{l}\text { Studies employing only } \\
\text { quantitative methodology } \\
N=58\end{array}$ & $\begin{array}{l}\text { Studies with mixed (qualitative } \\
\text { and quantitative) methodology } \\
\mathrm{N}=8\end{array}$ \\
\hline Total number of patients & 24,336 & 334 & 23,539 & 463 \\
\hline Female sex $\mathrm{N}^{\mathrm{a}}$ & 18,032 & 201 & 17,577 & 254 \\
\hline Age of participants (mean $\pm S D)^{a}$ & $54.9 \pm 5.0$ & $56.4 \pm 7.2$ & $54.5 \pm 4.8$ & $56.3 \pm 2.1$ \\
\hline Disease duration in years $(\text { mean } \pm S D)^{a}$ & $10.7 \pm 6.0$ & $13.9 \pm 7.2$ & $10.1 \pm 5.9$ & $11.2 \pm 4.2$ \\
\hline \multicolumn{5}{|c|}{$\begin{array}{l}\text { Method used for assessment of fears and/or beliefs } \\
N(\%) \text { of articles using the method }{ }^{b}\end{array}$} \\
\hline Individual interviews & $17(20.2)$ & $13(72.2)$ & NA & $4(50.0)$ \\
\hline Focus groups & $5(6.0)$ & $4(22.2)$ & NA & $1(12.5)$ \\
\hline Individual interviews and focus groups & $1(1.2)$ & $1(5.6)$ & NA & $0(0.0)$ \\
\hline Questionnaire & $63(75.0)$ & NA & $58(100.0)$ & $5(62.5)$ \\
\hline
\end{tabular}

$S D$ standard deviation, $N$ number, $N A$ non applicable

${ }^{a}$ Numbers calculated on available data

${ }^{\text {b}}$ The final result can be greater than $100 \%$ since some articles employed more than one method to assess fear and/or beliefs

of participants and fears/beliefs occurred in $7.1 \%$ of articles when describing study design and in $5.7 \%$ of publication when demographic data of patients were analyzed. All disagreements were solved by consensus. There were no disagreements about fears and beliefs presented in the publications.

\section{Fears}

Thirty two articles $(38.0 \%$ of the 84 analyzed publications) reported fears experienced by AR patients (Table 2). Articles reporting patient's concerns about pharmacological therapy and/or reporting factors that influenced these fears about drugs were the most

Table 2 Fears of people living with RA reported in the analyzed articles

\begin{tabular}{|c|c|c|c|c|c|}
\hline Fears & $\begin{array}{l}\text { Articles } \\
N \text { (\% of the } \\
32 \text { articles } \\
\text { reporting } \\
\text { fears) }{ }^{a}\end{array}$ & $\begin{array}{l}\text { Total } \\
\text { number of } \\
\text { patients }\end{array}$ & $\begin{array}{l}\mathrm{N}(\%) \text { of studies recruiting } \\
\text { participants in Europe in } \\
\text { each category/ Number of } \\
\text { patients recruited in Europe }\end{array}$ & $\begin{array}{l}\mathrm{N}(\%) \text { of studies recruiting } \\
\text { participants in North } \\
\text { America / Number of } \\
\text { patients recruited in } \\
\text { North America }\end{array}$ & $\begin{array}{l}\mathrm{N}(\%) \text { of studies recruiting participants } \\
\text { outside Europe and North America / } \\
\text { Number of patients recruited outside } \\
\text { Europe and North America }\end{array}$ \\
\hline $\begin{array}{l}\text { Fears related to } \\
\text { pharmacological } \\
\text { therapy }\end{array}$ & $16(50.0)$ & 1085 & $\begin{array}{l}13 \text { (81.3) / } 867 \text { (760 in UK, } \\
101 \text { in Netherlands, } 6 \text { in } \\
\text { Sweden) }\end{array}$ & $\begin{array}{l}2 \text { (12.5) /78 (60 in } \\
\text { Canada, } 18 \text { USA) }\end{array}$ & 1(6.2)/140 (140 in Egypt) \\
\hline $\begin{array}{l}\text { Fear of consequences } \\
\text { of disease in the future } \\
\text { and disability }\end{array}$ & $9(28.1)$ & 1049 & $\begin{array}{l}6 \text { (66.7) / } 707 \text { (460 in UK, } \\
199 \text { in Greece, } 48 \text { in Sweden) }\end{array}$ & $1(11.1) / 30$ (30 in USA) & $\begin{array}{l}2 \text { (22.2) /312 (101 in United } \\
\text { Arab Emirates, } 211 \text { in Australia) }\end{array}$ \\
\hline $\begin{array}{l}\text { Fears related to } \\
\text { pregnancy and } \\
\text { parenting role }\end{array}$ & $3(9.4)$ & 211 & $\begin{array}{l}3 \text { (100.0) / } 211 \text { (102 in UK, } 25 \\
\text { in France, } 84 \text { in Netherlands) }\end{array}$ & - & - \\
\hline Fear of falling & $3(9.4)$ & 5172 & 1(33.3)/48 (48 in Sweden) & $\begin{array}{l}1(33.3) / 128 \text { (128 in } \\
\text { USA) }\end{array}$ & 1 (33.3) / 4996 (4996 in Japan) \\
\hline $\begin{array}{l}\text { Fear of exercise } \\
\text { related injury/ fear } \\
\text { of exercise increasing } \\
\text { RA symptoms }\end{array}$ & $3(9.4)$ & 4289 & $\begin{array}{l}3 \text { (100.0) / } 4289 \text { (4283 in } \\
\text { Sweden, } 6 \text { in UK) }\end{array}$ & - & - \\
\hline $\begin{array}{l}\text { Fear to disturb other } \\
\text { people }\end{array}$ & $2(6.3)$ & 38 & $1(50.0) / 8$ (8 in UK) & $1(50.0) / 30$ (30 in USA) & - \\
\hline Fear of infections & $2(6.3)$ & 54 & $\begin{array}{l}2(100.0) / 54 \text { (48 in Sweden, } \\
6 \text { in UK) }\end{array}$ & - & - \\
\hline $\begin{array}{l}\text { Fear of negative } \\
\text { evaluation from } \\
\text { other people due } \\
\text { to appearance }\end{array}$ & $1(3.1)$ & 89 & $1(100.0) / 89$ (89 in UK) & - & - \\
\hline
\end{tabular}


reported (50.0\% of the 32 articles reporting fears, $N=16$ ). Fears about pharmacological therapy were related to both synthetic and biological DMARDs (Table 3). Beliefs about drugs seemed to change with the course of disease and personal experiences with the drug [4, 13-15]; according to Ostlund et al., for example, initial beliefs and expectations about methotrexate were challenged as patients initiated treatment and began experiencing varying degrees of effectiveness and side effects [13]. Demographic factors, such as age and educational level were also found to influence fear about drugs, with older patients and subjects with lower educational level experiencing higher concern about DMARDs $[5,6,14]$. People with RA and different ethnicities may have different views about DMARDS even when they are living in the same country: Kumar et al. described higher concern about drugs among RA patients with an Asiatic origin living in United Kingdom when compared with White British patients who lived in the same country $[6,16]$.

Fear of disease progression and disability was the second most described category $(N=9 / 32$ articles reporting fears, 28.1\%) (Table 2);

Fears related to pregnancy and parenting roles were reported in three articles $(9.4 \%$ of the 32 articles

Table 3 Fears related to synthetic and biological DMARDs

\begin{tabular}{|c|c|}
\hline Fears & Author and year of publication \\
\hline Fear of treatment failure & Sanderson 2009 [60] \\
\hline Fear of being taken of a drug & Sanderson 2009 [60] \\
\hline $\begin{array}{l}\text { Fear of side effects of treatment } \\
\text { (mainly long- term side effects) }\end{array}$ & $\begin{array}{l}\text { Goodacre } 2004 \text { [4] } \\
\text { Popa-Lisseanu 2005 [61] } \\
\text { Wong } 2007[5] \\
\text { Sanderson 2009 [60] } \\
\text { Fitzcharles 2009 [62] } \\
\text { Kumar } 2011[43] \\
\text { Van den Bent 2011 [63] } \\
\text { Hayden } 2015[14] \\
\text { Gadallah } 2015[42] \\
\text { Pasma } 2015[15] \\
\text { Nota } 2015[64]\end{array}$ \\
\hline $\begin{array}{l}\text { Fear of "too many pills/too many } \\
\text { drugs", fear of over-prescription }\end{array}$ & $\begin{array}{l}\text { Popa-Lisseanu } 2005 \text { [61] } \\
\text { Wong } 2007 \text { [5] } \\
\text { Fitzcharles 2009 [62] }\end{array}$ \\
\hline Fear of drug interaction & Fitzcharles 2009 [62] \\
\hline Fear of addiction & $\begin{array}{l}\text { Goodacre } 2004[4] \\
\text { Wong } 2007[5] \\
\text { Sanderson 2009 [60] } \\
\text { Fitzcharles } 2009 \text { [62] } \\
\text { Kumar } 2011[43] \\
\text { Van den Bent 2011 [63] } \\
\text { Nota 2015 [64] }\end{array}$ \\
\hline Fear of masking disease & Fitzcharles 2009 [62] \\
\hline $\begin{array}{l}\text { Fear of drugs causing reduced life } \\
\text { expectancy }\end{array}$ & Goodacre 2004 [4] \\
\hline $\begin{array}{l}\text { Fear of being disappointed with } \\
\text { a new treatment }\end{array}$ & Nyman 1999 [46] \\
\hline Fear of too many changes in therapy & Kumar 2011 [43] \\
\hline
\end{tabular}

reporting fears) (Table 2). Patients who participated in these articles were recruited in Europe and reported the fear of drugs causing birth defects, fear of genetic transfer, fear of being unable to fulfill parenting roles, fear of not being able to prevent accidents and fear of dropping a small baby or toddler [17-19].

Other reported concerns were: the fear of falling $(N=3 / 32$ articles, 9.4\%), the fear of exercise related injury/ fear of having symptoms increased by exercise $(\mathrm{N}=3 / 32$ articles, 9.4\%) and fear of negative evaluation from other people due to appearance $(N=1 / 32$ articles, 3.1\%).

Some examples of the fear to disturb other people $(N=2 / 32$ articles, $6.3 \%)$ included: the fear to disturb family members and partners at home due to night pain, fear to disturb other patients and nurses in the hospital due to night pain, the fear of taking the spouses' time and giving them too much responsibilities [20, 21].

Patients with RA also reported fear of infections such as catching colds; these fears were reported in 6.3\% $(\mathrm{N}=2)$ of those articles reporting fears. Some patients were afraid of taking exercise in public places such as swimming pools because they thought that having RA made them more susceptible to infections [22, 23].

Only four articles ( $12.5 \%$ of those reporting fears) included patients living outside Europe and North America. No articles reported fears of patients from Latin America or Africa.

\section{Beliefs}

Seventy-four articles, corresponding to $88.0 \%$ of the total 84 analyzed articles, reported at least one belief. Main categories of beliefs and their consequences were described in Table 4.

\section{Patient's beliefs about RA influenced impact of disease and assessment of health domains}

Patients' beliefs were reported to influence the impact of RA $(N=33,44.6 \%$ of the 74 articles assessing beliefs), mediated by their consequences in 8 health domains (Table 4).

Beliefs affecting the emotional domain were reported in 14/74 articles (18.9\%). Perceptions of greater symptomatology and greater stress, beliefs on serious consequences of RA, beliefs on lower ability to handle or cope with disease and beliefs on its owns responsibility in the development of RA were reported to amplify the negative emotional impact of disease and contribute to depressive mood and anxiety [24-29].

Patients' beliefs affecting measures of function were reported in 6 publications $(8.1 \%$ of articles reporting beliefs). Among RA patients, helplessness (patients' 
beliefs that they were not able to control pain and the course of disease) has a lower but statistically significant correlation with disability [30]. People who attributed more symptoms to RA, believe in a long illness duration, and held stronger beliefs that it would have negative consequences also presented greater disability on disease-specific measures of functioning; on the other side, stronger beliefs of personal control were associated with lower levels of disability, as were stronger beliefs in the ability of treatment to control RA [6, 26, 31-33].

Health-related quality of life (HRQOL) was found to be influenced by patients' beliefs in 5 articles (6.8\% of the 72 publications assessing beliefs). Fears about the consequences of the RA were independently correlated to physical HRQOL, i.e., patients who believe in worse consequences of RA had worse scores in the physical component of quality of life measures; patient global assessment of disease activity was also a significant predictor of poor mental and physical HRQOL [6, 33-36].

Other health domains affected by patients' beliefs were: fatigue (2.7\% of the publications assessing beliefs, $N=2$ articles), pain ( $2.7 \%, \mathrm{~N}=2)$, well-being $(2.7 \%, \mathrm{~N}=2)$, disease activity $(1.4 \%, N=1)$ and sexual life $(1.4 \%, \mathrm{~N}=1)$.

Among the 33 articles reporting consequences of patients' beliefs on health domains, only one manuscript recruited RA patients living outside Europe and North America.

\section{Beliefs about pharmacological and non-pharmacological therapy affected patients' adherence}

Beliefs about pharmacological and non-pharmacological therapy, including exercise and devices, were sometimes found to affect adherence to therapy $(17.6 \%$ of articles reporting beliefs, $N=13)$. Among the 13 articles in this category, four publication (30.8\%) studied the influence of patients' beliefs on adherence to physical activity. These references concluded that patient's beliefs about the usefulness of exercise for managing disease and their perceptions of positive social support for participation in exercise were highly correlated with physical activity participation [37-40]. Other eight articles in the same category (61.5\%) analyzed the consequences of patients' beliefs about drugs on adherence. Although most patients with RA believed their synthetic and biological DMARDS were necessary to preserve joint structures, reduce pain and increase quality of life, levels of concern about side effects were high and related to non-adherence $[3,5,15,16,41-44]$.

Table 4 Beliefs of people living with rheumatoid arthritis reported in the analyzed articles

\begin{tabular}{|c|c|c|c|c|c|}
\hline Beliefs and their consequences & $\begin{array}{l}\text { Articles } \\
\mathrm{N}(\% \text { of the } \\
74 \text { articles } \\
\text { reporting beliefs) }\end{array}$ & $\begin{array}{l}\text { Total } \\
\text { number } \\
\text { of patients }\end{array}$ & $\begin{array}{l}\text { Studies recruiting } \\
\text { participants in } \\
\text { Europe } \\
N(\%) / \text { Number } \\
\text { of patients recruited } \\
\text { in Europe }\end{array}$ & $\begin{array}{l}\text { Studies recruiting } \\
\text { participants in } \\
\text { North America } \\
\mathrm{N}(\%) \text { / } \\
\text { Number of patients } \\
\text { recruited in North } \\
\text { America }\end{array}$ & $\begin{array}{l}\text { Studies recruiting } \\
\text { participants outside } \\
\text { Europe and } \\
\text { North America } \\
\mathrm{N}(\%) / \\
\text { Number of patients } \\
\text { recruited outside } \\
\text { Europe and North } \\
\text { America }\end{array}$ \\
\hline Beliefs about the RA affecting impact of disease & $33(44.6)$ & 9146 & & & \\
\hline Emotional impact & $14(18.9)$ & 6404 & $6(42.9) / 901$ & $7(50.0) / 945$ & $1(7.1) / 4558$ \\
\hline Function & $6(8.1)$ & 715 & $4(66.7) / 370$ & $2(33.3) / 345$ & - \\
\hline Quality of life & $5(6.8)$ & 1034 & $4(80.0) / 623$ & $1(20.0) / 411$ & - \\
\hline Fatigue & $2(2.7)$ & 186 & $1(50.0) / 64$ & $1(50.0) / 122$ & - \\
\hline Pain & $2(2.7)$ & 299 & - & $2(100.0) / 299$ & - \\
\hline Well being & $2(2.7)$ & 123 & - & $2(100.0) / 123$ & - \\
\hline Disease activity & $1(1.4)$ & 322 & $1(100.0) / 322$ & - & - \\
\hline Sexual life & $1(1.4)$ & 63 & $1(100.0) / 63$ & - & - \\
\hline $\begin{array}{l}\text { Beliefs about pharmacological and non- } \\
\text { pharmacological therapy affecting adherence }\end{array}$ & $13(17.6)$ & 2464 & $10(77.0) / 1999$ & $2(15.4) / 325$ & $1(7.6) / 140$ \\
\hline $\begin{array}{l}\text { Beliefs about cause of disease affecting coping } \\
\text { strategies and adherence }\end{array}$ & $9(12.1)$ & 961 & $8(88.9) / 750$ & - & $1(11.1) / 211$ \\
\hline Beliefs affecting decision on therapy & $1(1.4)$ & 142 & - & $1(100.0) / 142$ & - \\
\hline $\begin{array}{l}\text { Beliefs affecting detection, tolerance and reporting } \\
\text { of side effects }\end{array}$ & $1(1.4)$ & 29 & $1(100.0) / 29$ & - & - \\
\hline
\end{tabular}




\section{Beliefs about cause of disease predicted copping patterns and adherence}

Beliefs about cause of disease expressed by RA patients in 9 studies (12.1\% of articles reporting beliefs) included: hereditarity, stress, unexpressed grief, diet, occupational factors/overwork, lack of exercise, God's will, weather conditions, biological reasons/immune system failure/autoimmunity, accident/chance and karmic explanation (disease caused by past "bad" actions) [18, 36, 43, 45-50]. Beliefs about cause of disease predicted copping patterns: Salminem et al., for example, observed that $40.0 \%$ of RA patients believe diet contributed to their disease, more so if longer disease duration and higher education and 51\% changed their diet after diagnosis, usually reducing consumption of animal fat and red meat [45].

Nyman et al. also showed that psychological factors, such as stress, overwork, anxiety or a distressing life event, for example bereavement or divorce were cited by $59.7 \%$ of AR patients as triggers factors leading to disease [46]. Other authors also demonstrated that most part of RA patients believe the cause of their disease was psychological in nature and that RA patients more readily admitted that psychological factors contributed to their illness compared to osteoarthritis patients [36, 50]. The psychological attribution as cause of RA seemed to have negative consequences: it was positively correlated with patient-related delay between beginning of symptoms and the first visit with general practitioner as well as with the tendency to use dysfunctional coping strategies [47, 49].

The analyzed work also described that patients who believed that the cause of RA was a biological one, viewed medicines less negatively than those who held the view that stress, God or fate were important causative factors [43].

\section{Patients' beliefs influenced decision making during clinical visits}

One article (1.4\% of the 74 articles reporting beliefs) concluded that patient's beliefs about consequences of RA and high level of concern about disease were more likely to have their treatment escalated, independently of disease activity [51]. In this work, high disease activity was not associated with future escalation of treatment in patients reporting low levels of perceived consequences, concern, and emotional impact; the combination of disease activity and illness beliefs better predicted future escalation of treatment in RA patients than either factor in isolation [51].

\section{Beliefs about DMARDs affected detection, tolerance and reporting of side effects}

One qualitative study $(1.4 \%$ of the 74 articles reporting beliefs) reported a relation between patients' beliefs about DMARDs and the reporting of side effects, with people more prepared to tolerate and do not report side effects when medication was perceived as beneficial or the number of alternatives perceived as limited. When DMARDs were not perceived as beneficial, concerns about side effects were voiced more frequently and the rationale for continued use was questioned [4].

Among the 74 articles reporting beliefs, only three (4.0\%) described perceptions of patients with RA living outside Europe and North America (Table 4).

When all the 84 articles were analyzed, only $9.5 \%(N=8)$ of them reported fears and/or beliefs of patients living outside Europe and North America: there was only one work which recruited patients in Latin America and no article included patients from Africa.

\section{Discussion}

This systematic literature review demonstrated that patients with RA have several beliefs about disease and its treatment and these beliefs influenced global impact of disease, adherence to therapy and copping patterns. Fears regarding the use of DMARDs and the fear of functional disability due to disease progression were the most reported in literature. It also highlighted areas where further original research is required: studies assessing patients' fears and beliefs were conducted mainly in Europe and North America and there is limited knowledge on fears and beliefs of patients living with RA in Asia, Africa, Latin America and Oceania.

Beliefs were shown to influence the patient-perceived impact of RA and, specially, the emotional / psychological impact of disease. This fact seems to be relevant since the prevalence of depression and anxiety is significant among people with RA [52]. Health professionals responsible for the management of RA patients should try to identify unjustified fears and erroneous beliefs that could amplify the psychological impact of disease. To minimize the patients' feeling of culpability by clarifying wrong beliefs about cause of disease, as well as to reinforce patients' ability to cope with consequences of RA are some strategies that can be adopted by health professionals. Since patients who attribute more symptoms to the rheumatic disease have higher psychological impact, it seems appropriate to help patients to recognize symptoms that are really attributed to RA and to differentiate them from those caused by comorbidities such as depression, anxiety and fibromyalgia [24, 28].

Although the emotional domain was the most cited, outcome measures evaluating other health domains as function, quality of life, pain and fatigue were also influenced by patients' perceptions. Since beliefs in more severe consequences of rheumatic disease and feelings of helplessness were associated with worse outcome measures of functioning it is convenient to 
consider beliefs when facing to patients with poor function not otherwise explained by disease activity $[26,30,32,33]$.

Moreover, this systematic literature review provides rheumatologists new evidence to consider patient's fears and beliefs when facing people with RA who are nonadherent to therapy. Recent work, which used pharmacy dispensing data to calculate medication possession ratios (MPR) and determine patients' adherence (MPR $\geq 0.80$ ), demonstrated that patients with RA have low adherence to conventional and biological DMARDs [53, 54]. MenaVazquez et al. found that $88.8 \%$ of RA patients showed good adherence to biological drugs but only $61.2 \%$ also correctly took concomitant conventional synthetic DMARDs [54]. Another work from Calip et al. found lower rates of adherence to biological therapy: only 37. $0 \%$ of RA patients were adherent, and the lower rates of adherence $(17.0 \%)$ were found among young patients in their third year of treatment [53]. Fears related to pharmacological therapy were the most reported in our literature review and almost $20.0 \%$ of articles reported that patients' beliefs about therapy were found to affect adherence to treatment, reinforcing the idea that fears and beliefs may have an important role in explaining non-adherence. Since the fear of functional disability was the second most described patients' concern, it could be a strategy to increase adherence to DMARDS to instruct the patients about the ability of these drugs to avoid future structural damage and loss of function.

Although it seems plausible that to offer better knowledge on RA treatment could be a good strategy to improve non-adherence, some authors found that motivationalinterviewing-guided group sessions about DMARDs use were not effective to change patients' beliefs about necessity of these drugs and concerns about therapy; this intervention did not improved rates of non-adherence [55]. Van den Bent et al. tested another intervention aiming to change patients' beliefs about medicines and improve nonadherence: a written report informing the physician about the medicine use and the adherence rate was sent to the rheumatologist by the researcher [56]. Adherence did not change after the intervention, compared to adherence assessment prior to the intervention and beliefs about medication were not significantly altered [56]. Further research is necessary to ensure effective strategies aiming to reduce erroneous fears and beliefs that could negatively affect the adherence to therapy in RA patients.

This work brings to light the paucity of published articles reporting fears and/or beliefs of RA patients living in Latin America, Africa, Oceania and Asia. Since nationality was found to influence, among RA patients, the perceptions about trust in physicians and the choice of the RA priority domains, it is convenient to rheumatologists working outside Europe and
North America to gain more insight on fear and beliefs of their patients $[7,57]$.

In addition to differences among nationalities, the diversity of opinions among distinct ethnical groups living in the same country also exists; in United Kingdom, for example, Kumar et al. demonstrated that non-English-speaking RA patients (patients of South Asian origin) usually believe that RA is caused by a God's will and that they do not have an active role in therapy, while English-speaking patients usually believe that the cause of disease is a biological one and view DMARDs less negatively [43]. Salminem et al. also interviewed Punjabi women living in United Kingdom and remarked that this group made sense of the development of RA as a consequence of past "bad" actions. This "karmic explanation" to the development of disease lead patients to hide symptoms from others in order to avoid a moral judgement and stigmatization [48]. Further research comparing fear and beliefs among people of different ethnic and cultural backgrounds would be interesting.

Other gap in publications was remarked: most articles included only patients with long disease duration, and the perception of patients with early RA was rarely described [58]. Further studies allowing comparison of fear and beliefs of patients in different stages of RA is necessary since it has been shown that beliefs about the consequences of disease and expectations of patients varied according to the stage of RA and familiarity with other people with the same clinical condition $[13,18]$.

This study has some weaknesses. It is not exhaustive since the one database assessed was PubMed/Medline; however this is the most important database of biomedical research articles covering more than 5600 journals published in more than 80 countries; articles in five languages were included in the analysis and there was no limit of date for the search.

This work included all studies reporting fear and/or beliefs of patients with RA found with our search strategy regardless of their quality level to optimize the number of reported fear and beliefs. The appraisal of qualitative research, for example, is still a challenge since there is no consensus on a tool for quality evaluation in this type of studies. According to Dixon-Woods et al., there are over 100 tolls described to evaluate quality in qualitative research, some adopting non-reconcilable positions on a number of issues [59].

It is possible that among the studies employing some method of qualitative analysis, some work were probably not exhaustive since less than a quarter of those articles reported that the principle of saturation was used to define the sample size [9]. 
Despite its limitations, this work highlights several fears and beliefs of patients with RA, allowing rheumatologists and other health professionals to create strategies to minimize fears and beliefs that could affect negatively the management of disease.

\section{Conclusion}

In RA, patients' beliefs influenced global impact of disease, adherence to therapy and copping patterns. The most common fears of RA patients were related to the consequences of RA and the use of DMARDs. Further research is needed on fears and beliefs of patients living outside Europe and North America.

\section{Additional file}

Additional file 1: List of the 84 articles included in the analysis.

(DOCX $28 \mathrm{~kb}$ )

\section{Abbreviations}

BMQ: Beliefs about medicines questionnaire; DMARDs: Disease- modifying antirheumatic drugs; HRQOL: Health-related quality of life; IPQ: IIIness perception questionnaire; MPR: Medication possession ratios; RA: Rheumatoid arthritis

\section{Funding}

The first author P Palominos conducted this project with own resources. Professor Ricardo Machado Xavier has received a grant for research from CNPq -National Council for Scientific and Technological Development.

\section{Availability of data and materials}

Dr. Palominos detain the data and agree to share it with reviewers and editors if necessary.

\section{Authors' contributions}

All authors meet the authorship criteria, giving substantial contribution to the conception of the work, data acquisition and analysis, drafting or reviewing the work for intellectual content and giving final approval of the version to be published. The authors agree to be accountable for all aspects of the work in ensuring that questions related to the accuracy or integrity of any part of the work are appropriately investigated and resolved.

Ethics approval and consent to participate

Not applicable.

\section{Consent for publication}

All authors consent to publish the manuscript in Advances in Rheumatology.

\section{Competing interests}

The authors declare that they have no competing interests.

\section{Publisher's Note}

Springer Nature remains neutral with regard to jurisdictional claims in published maps and institutional affiliations.

\section{Author details}

${ }^{1}$ Universidade Federal do Rio Grande do Sul (UFRGS), Programa de Pós Graduação em Ciências Médicas (PPGCM), Rua Ramiro Barcelos 2400, segundo andar, Porto Alegre 90035-903, Brazil. ²Department of Rheumatology, Hospital de Clinicas de Porto Alegre, Rua Ramiro Barcelos 2350, sexto andar, Porto Alegre 90035-903, Brazil. ${ }^{3}$ Sorbonne Universités, UPMC Univ Paris 06, Institut Pierre Louis d'Epidémiologie et de Santé Publique, GRC-UPMC 08 (EEMOIS); Department of Rheumatology, Pitié Salpêtrière Hospital, AP-HP, 47-83 Boulevard de l'Hôpital, 75013 Paris, France.
Received: 20 February 2018 Accepted: 29 March 2018

Published online: 24 May 2018

\section{References}

1. Gossec L, Dougados M, Dixon W. Patient-reported outcomes as end points in clinical trials in rheumatoid arthritis. RMD Open. 2015;1(1):e000019.

2. Kalyoncu U, Dougados M, Daurès J-P, Gossec L. Reporting of patientreported outcomes in recent trials in rheumatoid arthritis: a systematic literature review. Ann Rheum Dis. 2009;68(2):183-90.

3. Neame R, Hammond A. Beliefs about medications: a questionnaire survey of people with rheumatoid arthritis. Rheumatology. 2005:44(6):762-7.

4. Goodacre LJ, Goodacre JA. Factors influencing the beliefs of patients with rheumatoid arthritis regarding disease-modifying medication. Rheumatology. 2004;43(5):583-6.

5. Wong M, Mulherin D. The influence of medication beliefs and other psychosocial factors on early discontinuation of disease-modifying antirheumatic drugs. Musculoskeletal Care. 2007;5(3):148-59.

6. Kumar K, Gordon C, Toescu V, Buckley CD, Horne R, Nightingale PG, et al. Beliefs about medicines in patients with rheumatoid arthritis and systemic lupus erythematosus: a comparison between patients of south Asian and white British origin. Rheumatology. 2008;47(5):690-7.

7. Berrios-Rivera J, Street R Jr, Popa-Lisseanu M, Kallen M, Richardson M, Janssen N. Trust in physicians and elements of the medical interaction in patients with rheumatoid arthritis and systemic lupus erythematosus. Arthritis Rheum. 2006;55(3):385-93.

8. PRISMA: transparent report of systematic reviews and metanalysis. Acessed 1 May 2017

9. Depoy E, Gitlin L. Introduction to research: understanding and applying multiple strategies. Fourth Edi. St. Louis: Elsevier, Mosby; 1998.

10. Weinman J, Petrie K, Moss-Morris R, Horne R. The illness perception questionnaire: a new method for assessing illness perceptions. Psychology and Health Psychol Heal. 1996;11:431-46.

11. Broadbent E, Petrie KJ, Main J, Weinman J. The brief illness perception questionnaire. J Psychosom Res. 2006;60(6):631-7.

12. Horne R, Weinman J, Hankins $M$. The beliefs about medicines questionnaire: the development and evaluation of a new method for assessing the cognitive representation of medication. Psychol Health. 1999;14(1):1-24.

13. Östlund G, Björk M, Valtersson E, Sverker A. Lived experiences of sex life difficulties in men and women with early RA - the Swedish TIRA project. Musculoskeletal Care. 2015;13(4):248-57.

14. Hayden C, Neame R, Tarrant C. Patients' adherence-related beliefs about methotrexate: a qualitative study of the role of written patient information. BMJ Open. 2015;5(5):e006918.

15. Pasma A, Van't Spijker A, Luime JJ, Walter MJM, Busschbach JJV, Hazes JMW. Facilitators and barriers to adherence in the initiation phase of diseasemodifying antirheumatic drug (DMARD) use in patients with arthritis who recently started their first DMARD treatment. J Rheumatol. 2015;42(3):379-85.

16. Kumar K, Raza K, Nightingale P, Horne R, Chapman S, Greenfield S, et al. Determinants of adherence to disease modifying anti-rheumatic drugs in white British and south Asian patients with rheumatoid arthritis: a cross sectional study. BMC Musculoskelet Disord. 2015;16(1):396.

17. Barlow JH, Cullen LA, Rowe IF. Comparison of knowledge and psychological well-being between patients with a short disease duration ( $\leq 1$ year) and patients with more established rheumatoid arthritis ( $\geq 10$ years duration). Patient Educ Couns. 1999;38(3):195-203.

18. Berenbaum F, Chauvin P, Hudry C, Mathoret-Philibert F, Poussiere M, De Chalus T, et al. Fears and beliefs in rheumatoid arthritis and spondyloarthritis: a qualitative study. PLoS One. 2014;9(12):e114350.

19. Clowse MEB, Chakravarty E, Costenbader KH, Chambers C, Michaud K. Effects of infertility, pregnancy loss, and patient concerns on family size of women with rheumatoid arthritis and systemic lupus erythematosus. Arthritis Care Res (Hoboken). 2012;64(5):668-74.

20. Coady DA, Armitage C, Wright D. Rheumatoid arthritis patients' experiences of night pain. J Clin Rheumatol. 2007;13(2):66-9.

21. Foxall MJ, Kollasch C, McDermott S. Family stress and coping in rheumatoid arthritis. Arthritis Care Res (Hoboken). 1989;2(4):114-21.

22. Wang M, Donovan-Hall M, Hayward H, Adams J. People's perceptions and beliefs about their ability to exercise with rheumatoid arthritis: a qualitative study. Musculoskeletal Care. 2015;13(2):112-5.

23. Östlund G, Björk M, Thyberg I, Thyberg M, Valtersson E, Stenström B, et al. Emotions related to participation restrictions as experienced by patients 
with early rheumatoid arthritis: a qualitative interview study (the Swedish TIRA project). Clin Rheumatol. 2014;33(10):1403-13.

24. Van Os S, Norton S, Hughes LD, Chilcot J. Illness perceptions account for variation in positive outlook as well as psychological distress in rheumatoid arthritis. Psychol Health Med. 2012;17(4):427-39.

25. Strahl C, Kleinknecht RA, Dinnel DL. The role of pain anxiety, coping, and pain self-efficacy in rheumatoid arthritis patient functioning. Behav Res Ther. 2000:38(9):863-73

26. Smith C. A, Wallston $\mathrm{K}$ a. Adaptation in patients with chronic rheumatoid arthritis: application of a general model. Health Psychol. 1992;11(3):151-62.

27. Lowe R, Cockshott Z, Greenwood R, Kirwan JR, Almeida C, Richards P, et al. Self-efficacy as an appraisal that moderates the coping-emotion relationship: associations among people with rheumatoid arthritis. Psychol Health. 2008;23(2):155-74.

28. Devins GM, Gupta A, Cameron J, Woodend K, Mah K, Gladman D. Cultural syndromes and age moderate the emotional impact of illness intrusiveness in rheumatoid arthritis. Rehabil Psychol. 2009:54:33-44. 12p

29. Nakajima A, Kamitsuji S, Saito A, Tanaka E, Nishimura K, Horikawa N, et al. Disability and patient's appraisal of general health contribute to depressed mood in rheumatoid arthritis in a large clinical study in Japan. Mod Rheumatol. 2006;16(3):151-7.

30. Nicassio PM, Kay MA, Custodio MK, Irwin MR, Olmstead R, Weisman MH. An evaluation of a biopsychosocial framework for health-related quality of life and disability in rheumatoid arthritis. J Psychosom Res. 2011;71(2):79-85.

31. Scharloo M, Kaptein AA, Weinman J, Hazes JM, Willems LNA, Bergman W, et al. Illness perceptions, coping and functioning in patients with rheumatoid arthritis, chronic obstructive pulmonary disease and psoriasis. J Psychosom Res. 1998:44(5):573-85.

32. Serbo B, Jajic I. Relationship of the functional status, duration of the disease and pain intensity and some psychological variables in patients with rheumatoid arthritis. Clin Rheumatol. 1991;10(4):419-22.

33. Graves H, Scott DL, Lempp H, Weinman J. Illness beliefs predict disability in rheumatoid arthritis. J Psychosom Res. 2009;67(5):417-23.

34. Kotsis K, Voulgari PV, Tsifetaki N, Machado MO, Carvalho AF, Creed F, et al. Anxiety and depressive symptoms and illness perceptions in psoriatic arthritis and associations with physical health-related quality of life. Arthritis Care Res (Hoboken). 2012;64(10):1593-601.

35. Alishiri GH, Bayat N, Fathi Ashtiani A, Tavallaii SA, Assari S, Moharamzad Y. Logistic regression models for predicting physical and mental health-related quality of life in rheumatoid arthritis patients. Mod Rheumatol. 2008;18(6):601-8.

36. Kotsis K, Voulgari PV, Tsifetaki N, Drosos AA, Carvalho AF, Hyphantis T. Illness perceptions and psychological distress associated with physical health-related quality of life in primary Sjögren's syndrome compared to systemic lupus erythematosus and rheumatoid arthritis. Rheumatol Int. 2014;34(12):1671-81.

37. Ehrlich-Jones L, Lee J, Semanik P, Cox C, Dunlop D, Chang RW. Relationship between beliefs, motivation, and worries about physical activity and physical activity participation in persons with rheumatoid arthritis. Arthritis Care Res. 2011:63(12):1700-5.

38. Swardh E, Biguet G, Opava CH. Views on exercise maintenance: variations among patients with rheumatoid arthritis. Phys Ther. 2008;88(9):1049-60.

39. Sperber NR, Allen KD, DeVellis BM, DeVellis RF, Lewis MA, Callahan LF. Differences in effectiveness of the active living every day program for older adults with arthritis. J Aging Phys Act. 2013;21(4):387-401.

40. Iversen MD, Fossel AH, Daltroy LH. Rheumatologist-patient communication about exercise and physical therapy in the management of rheumatoid arthritis. Arthritis Care Res. 1999;12(3):180-92.

41. Morgan C, McBeth J, Cordingley L, Watson K, Hyrich KL, Symmons DPM, et al. The influence of behavioural and psychological factors on medication adherence over time in rheumatoid arthritis patients: a study in the biologics era. Rheumatol (United Kingdom). 2015;54(10):1780-91.

42. Gadallah MA, Boulos DNK, Gebrel A, Dewedar S, Morisky DE. Assessment of rheumatoid arthritis patients' adherence to treatment. Am J Med Sci. 2015; 349(2):151-6.

43. Kumar K, Gordon C, Barry R, Shaw K, Horne R, Raza K. "It's like taking poison to kill poison but I have to get better": a qualitative study of beliefs about medicines in rheumatoid arthritis and systemic lupus erythematosus patients of south Asian origin. Lupus. 2011;20(8):837-44.

44. Lendrem D, Mitchell S, McMeekin P, Bowman S, Price E, Pease CT, et al. Health-related utility values of patients with primary Sjögren's syndrome and its predictors. Ann Rheum Dis. 2014;73(7):1362-8.
45. Salminen E, Heikkilä S, Poussa T, Lagström H, Saario R, Salminen S. Female patients tend to alter their diet following the diagnosis of rheumatoid arthritis and breast cancer. Prev Med (Baltim). 2002;34(5):529-35.

46. Nyman CS, Lutzen K. Caring needs of patients with rheumatoid arthritis. Nurs Sci Q. 1999;12(2):164-9.

47. Van Der Elst K, De Cock D, Vecoven E, Arat S, Meyfroidt S, Joly J, et al. Are illness perception and coping style associated with the delay between symptom onset and the first general practitioner consultation in early rheumatoid arthritis management? An exploratory study within the CareRA trial. Scand J Rheumatol. 2016;45(3):171-8.

48. Sanderson T, Calnan M, Kumar K. The moral experience of illness and its impact on normalisation: examples from narratives with Punjabi women living with rheumatoid arthritis in the UK. Sociol Health IIIn. 2015;37(8): 1218-35.

49. Ziarko M, Mojs E, Piasecki B, Samborski W. The mediating role of dysfunctional coping in the relationship between beliefs about the disease and the level of depression in patients with rheumatoid arthritis. Sci World J. 2014;2014:585063

50. Ahern MJ, McFarlane AC, Leslie A, Eden J, Roberts-Thomson PJ. Illness behaviour in patients with arthritis. Ann Rheum Dis. 1995;54:245-50,

51. Fraenkel $L$, Cunningham M. High disease activity may not be sufficient to escalate care. Arthritis Care Res. 2014:66(2):197-203.

52. Isik A, Koca SS, Ozturk A, Mermi O. Anxiety and depression in patients with rheumatoid arthritis. Clin Rheumatol. 2007;26(6):872-8.

53. Calip GS, Adimadhyam S, Xing S, Rincon JC, Lee WJ, Anguiano RH. Medication adherence and persistence over time with self-administered TNF-alpha inhibitors among young adult, middle-aged, and older patients with rheumatologic conditions. Semin Arthritis Rheum. 2017 Oct;47(2):157-64.

54. Mena-Vazquez N, Manrique-Arija S, Yunquera-Romero L, Ureña-Garnica I, Rojas-Gimenez M, Domic C, et al. Adherence of rheumatoid arthritis patients to biologic disease-modifying antirheumatic drugs: a cross-sectional study. Rheumatol Int. 2017 Oct;37(10):1709-18.

55. Zwikker HE, Van den Ende CH, Van Lankveld WG, Den Broeder AA, Van den Hoogen FH, Van de Mosselaar B, et al. Effectiveness of a group-based intervention to change medication beliefs and improve medication adherence in patients with rheumatoid arthritis: a randomized controlled trial. Patient Educ Couns. 2014:94(3):356-61.

56. Van den Bemt BJF, den Broeder AA, van den Hoogen FHJ, Benraad B, Hekster YA, van Riel PLCM, et al. Making the rheumatologist aware of patients' non-adherence does not improve medication adherence in patients with rheumatoid arthritis. Scand J Rheumatol. 2011;40(3):192-6.

57. Wen H, Ralph Schumacher H, Li X, Gu J, Ma L, Wei H, et al. Comparison of expectations of physicians and patients with rheumatoid arthritis for rheumatology clinic visits: a pilot, multicenter, international study. Int J Rheum Dis. 2012;15(4):380-9.

58. Townsend A, Adam P, Cox SM, Li LC. Everyday ethics and help-seeking in early rheumatoid arthritis. Chronic IIIn. 2010;6(3):171-82.

59. Dixon-Woods M, Sutton A, Shaw R, Miller T, Smith J, Young B, et al. Appraising qualitative research for inclusion in systematic reviews: a quantitative and qualitative comparison of three methods. J Health Serv Res Policy. 2007;12(1):42-7.

60. Sanderson T, Calnan M, Morris M, Richards P, Hewlett S. The impact of patient-perceived restricted access to anti-TNF therapy for rheumatoid arthritis: a qualitative study. Musculoskeletal Care. 2009;7(3):194-209.

61. Popa-Lisseanu MGG, Greisinger A, Richardson M, O'Malley KJ, Janssen NM, Marcus DM, et al. Determinants of treatment adherence in ethnically diverse, economically disadvantaged patients with rheumatic disease. J Rheumatol. 2005;32(5):913-9.

62. Fitzcharles MA, DaCosta D, Ware MA, Shir Y. Patient barriers to pain management may contribute to poor pain control in rheumatoid arthritis. J Pain. 2009:10(3):300-5.

63. Van Den Bemt BJF, Den Broeder AA, Van Den Hoogen FHJ, Benraad B, Hekster YA, Van Riel PLCM, et al. Making the rheumatologist aware of patients' non-adherence does not improve medication adherence in patients with rheumatoid arthritis. Scand J Rheumatol. 2011:40(3):192-6.

64. Nota I, Drossaert CHC, Taal E, Van De Laar MAFJ. Patients' considerations in the decision-making process of initiating disease-modifying antirheumatic drugs. Arthritis Care Res. 2015;67(7):956-64. 